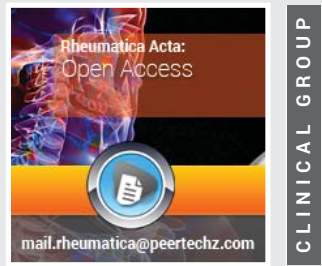

Rheumatica Acta:Open Access

\section{Sylvain Raoul Simeni Njonnou ${ }^{1,2 *}$, Muhammad Shahnawaz Soyfoo ${ }^{3}$ and Frederic-Alain Vandergheynst ${ }^{2}$}

'Department of Internal Medicine and Specialties, Faculty of Medicine and Biomedical Sciences, University of Yaounde I, Cameroon

${ }^{2}$ Department of Internal Medicine, Erasme Hospital, Université libre de Bruxelles, Belgium

${ }^{3}$ Department of Rheumatology, Erasme Hospital,

Université Libre de Bruxelles, Belgium

Received: 08 August, 2019

Accepted: 24 August, 2019

Published: 26 August, 2019

*Corresponding author: Sylvain Raoul Simeni Njonnou, Department of Internl Medicine, Faculty of Medicine and Biomedical Sciences, University of Yaoundé I. Department of Internal Medicine, erasme Hospital, Route de Lennik 808, 1070 Brussels, Belgium,

Tel: +3225553806; Fax: +3225553211;

E-mail: raoulsims@yahoo.fr;

sylvain.simeni.njonnou@erasme.ulb.ac.be

https://www.peertechz.com

\section{Check for updates}

We report the case of a 60 -year-old female patient who presented meningoencephalitis due to Neisseria meningitidis serogroup B in November 2018. She was admitted at the emergency department for febrile confusion lasting two days associated with one episode of vomiting. There was no visual disturbance, headache, photophobia or phonophobia. On physical examination, neck stiffness was observed but no other neurological focal sign was present. There was no cutaneous rash. Cerebral CT-scan was unremarkable. Blood cultures were negative. Given the presence of confusion and neck stiffness, a lumbar puncture with analysis of cerebrospinal fluid was performed, showing leucocyte count at $3080 / \mu \mathrm{L}$ (normal range $<5$ ), protein at $277 \mathrm{mg} / \mathrm{dL}$ (normal range 1545), glucose at $23 \mathrm{mg} / \mathrm{dL}$ (normal range 40-70), lactic acid at $13 \mathrm{mmol} / \mathrm{L}$ (normal range <2.4). Cerebrospinal fluid culture evidenced $\mathrm{N}$. meningitidis serogroup B sensitive to ceftriaxone, ciprofloxacin, and rifampicin. The patient was initially treated with intravenous ceftriaxone $4 \mathrm{~g}$ daily. Five days after the current admission, she developed oligoarthritis involving the left shoulder, right knee, and right ankle associated with lowgrade fever. A right knee joint aspiration was performed and showed an inflammatory fluid (leucocyte count at $18100 / \mu \mathrm{L}$ ). Microbial cultures were negative. Since the joint aspirate did not show any signs of ongoing local infection, non-steroid antiinflammatory drugs were added to treatment and ceftriaxone was prolonged until day 10. Real-time Polymerase Chain

Reaction (qPCR) identified N. meningitidis in the articular fluid. Ceftriaxone was administered for 10 days and relayed onwards with oral ciprofloxacin for a total of 6 weeks. There was no deficiency in complement factors. Table 1 summarizes all results.

Arthritis-related to N. meningitidis disease can occur with or without meningitis particularly in the setting of meningococcal disease $[1,2]$. Its prevalence is evaluated between 2 and $12.5 \%$ in the setting of meningococcal infection $[3,4]$. It is difficult

\title{
Table 1: Summary of results.
}

Day Test

\section{CSF cytology and} biochemy

Day1 CSF culture

Full blood count (FBC) CRP FBC Day 3

Day 5 CRP FBC CRP

Right knee joint aspirate cytology

Day 6 Right knee joint aspirate direct examination and culture qPCR \begin{tabular}{l|l} 
Day 10 & FBC \\
\hline & CRP
\end{tabular} Day 14

\section{Results}

leucocyte count: $3080 /$ microL (93\% neutrophils) protein: $277 \mathrm{mg} / \mathrm{dL}$ glucose: $23 \mathrm{mg} / \mathrm{dL}$ lactic acid: $13 \mathrm{mmol} / \mathrm{L}$

N. meningitidis serogroup $B$ Sensitive to ceftriaxone, ciprofloxacin, Rifampicin

Leucocytes: 16,400/ microL and neutrophil count $14,400 /$ microL

$$
430 \mathrm{mg} / \mathrm{L}
$$

Leucocytes 12,000/microL Neutrophils count $9,400 /$ microL

$$
75 \mathrm{mg} / \mathrm{L}
$$

Leucocytes 12,200/microL Neutrophils count $9,700 /$ microL

$$
110 \mathrm{mg} / \mathrm{L}
$$

leucocyte count: 18100/microL (64\% neutrophils)

$$
\text { Negative }
$$

N. meningitidis serogroup $B$

Leucocytes 12,300/microL Neutrophils count $9,600 /$ microL

$$
160 \mathrm{mg} / \mathrm{L}
$$

Leucocytes $8,400 / \mathrm{microL}$ Neutrophils count $6,500 / \mathrm{microL}$ $60 \mathrm{mg} / \mathrm{L}$ 
to differentiate septic and immune-mediated meningococcal arthritis (IMA), particularly after several days of antibiotherapy and a delayed occurrence of arthritis. However, making the adequate diagnosis is mandatory to adapt the antibiotherapy duration.

Clinical and biological characteristics were used to differentiate both entities. Schaad, in 1980, postulated that late-onset arthritis in N. meningitidis disease could evocate diagnosis of IMA [2]. Goedvoelk et al., evocated delayed fever and delayed increase of ESR and/or CRP as clues for the diagnosis of IMA [5]. In a recent publication, MassonBehar et al. differentiate IMA and septic by articular fluid culture: a negative culture was suggestive of IMA [6]. There are few description of the use of PCR for diagnosing septic meningococcal arthritis: Rousseau et al described the use of a $16 \mathrm{~S}$ universal PCR and O'Sullivan et al have reported the use of a multiplexed FilmArray ${ }^{\circledR}$ meningitis/encephalitis panel (MEP) for diagnosing meningococcal septic arthritis $[7,8]$. Given the high probability of septic meningococcal arthritis, we preferred to use a real-time PCR (qPCR). Its usefulness for diagnosing meningitis or invasive meningococcal disease is well known [9]. The sensitivity of qPCR for detecting $\mathrm{N}$. meningitidis is more than 3 times higher than culture (on CSF and blood cultures), making this exam the best test to exclude septic arthritis related to N. meningitidis [9].

Besides the initial misleading non-severe presentation of meningococcal meningitis, this case underlines the difficulties for differentiating IMA and septic meningococcal arthritis on the basis of clinical and classical microbiological clues. We report here the first use of a qPCR for detection of $\mathrm{N}$. meningitidis in the articular fluid.

\section{References}

1. Sud R, Bhatnagar MK, Sud A, Tiwari A (2009) Incidence and outcome of arthritis in meningococcal disease. J Indian Med Assoc mars 107: 158-159. Link: http://bit.ly/2P8015X

2. Schaad UB (1980) Arthritis in disease due to Neisseria meningitidis. Rev Infect Dis 2: 880-888. Link: http://bit.ly/2ZajCsN

3. Cabellos C, Nolla JM, Verdaguer R, Pelegrin I, Ribera A, et al. (2012) Arthritis related to systemic meningococcal disease: 34 years' experience. Eur $\mathrm{J}$ Clin Microbiol Infect Dis 31: 2661-2666. Link: http://bit.ly/2NuaJ6m

4. Weisfelt M, van de Beek D, Spanjaard L, de Gans J (2006) Arthritis in adults with community-acquired bacterial meningitis: a prospective cohort study. BMC Infect Dis 6: 64. Link: http://bit.ly/2KScvMR

5. Goedvolk CA, von Rosenstiel IA, Bos AP (2003) Immune complex associated complications in the subacute phase of meningococcal disease: incidence and literature review. Arch Dis Child 88: 927-930. Link: http://bit.ly/2TXma7P

6. Masson-Behar V, Jacquier H, Richette P, Ziza J-M, Zeller V, et al. (2017) Arthritis secondary to meningococcal disease: A case series of 7 patients. Medicine (Baltimore) 96: e7573. Link: http://bit.ly/2L3xgUG

7. Rousseau V, Descours G, Chaker M, Tristan A, Freydière AM, et al. (2012) Primary meningococcal B osteomyelitis and arthritis with multifocal pyomyositis in a child: a case report. Arch Pediatr 19: 1330-1333. Link: http://bit.ly/2P8iAc7

8. O'Sullivan D, Linnane B, Mostyn A, Jonathan N, Lenihan M, et al. (2018) Detection of Neisseria meningitidis in a paediatric patient with septic arthritis using multiplexed diagnostic PCR targeting meningitis/encephalitis (ME). Ann Clin Microbiol Antimicrob 17: 14. Link: http://bit.ly/2NtXXEE

9. Guiducci S, Moriondo M, Nieddu F, Ricci S, De Vitis E, et al. (2019) Culture and Real-time Polymerase Chain reaction sensitivity in the diagnosis of invasive meningococcal disease: Does culture miss less severe cases? PLOS ONE 14 e0212922. Link: http://bit.ly/2KPOqWR

\footnotetext{
Discover a bigger Impact and Visibility of your article publication with Peertechz Publications

Highlights

* Signatory publisher of ORCID

* Signatory Publisher of DORA (San Francisco Declaration on Research Assessment)

- Articles archived in worlds' renowned service providers such as Portico, CNKI, AGRIS, TDNet, Base (Bielefeld University Library), CrossRef, Scilit, J-Gate etc.

* Journals indexed in ICMJE, SHERPA/ROMEO, Google Scholar etc.

* OAI-PMH (Open Archives Initiative Protocol for Metadata Harvesting)

* Dedicated Editorial Board for every journal

* Accurate and rapid peer-review process

* Increased citations of published articles through promotions

- Reduced timeline for article publication

Submit your articles and experience a new surge in publication services (https://www.peertechz.com/submission).
}

Peertechz journals wishes everlasting success in your every endeavours.

Copyright: (c) 2019 Simeni Njonnou SR, et al. This is an open-access article distributed under the terms of the Creative Commons Attribution License, which permits unrestricted use, distribution, and reproduction in any medium, provided the original author and source are credited. 